\title{
Study of pregnancy dermatoses in patients attending outpatient of B P Koirala Institute of Health Sciences, Dharan, Nepal
}

\author{
Dawadi $P^{1}$, Rijal $A^{2}$, Uprety $D^{3}$ \\ ${ }^{1}$ Lecturer, Dermatology and Venereology KIST Medical College, Imadol Lalitpur Nepal, ${ }^{2}$ Professor \\ of Dermatology and Venereology, B P Koirala Institute of Health Sciences, Dharan Nepal, ${ }^{3}$ Professor \\ and Head, Department of Gynecology and Obstetrics, B P Koirala Institute of Health Sciences, Dharan \\ Nepal.
}

\begin{abstract}
Background: Pregnancy causes immense hormonal, vascular and immunologic changes affecting every organ system including skin. It can have a positive as well as a negative effect on the course of pre-existing skin diseases. Specific dermatoses of pregnancy constitute a heterogenous group of inflammatory dermatoses associated exclusively with pregnancy.
\end{abstract}

Objectives: To study the spectrum and frequency of pregnancy dermatoses and to compare the clinicoepidemiological profile of non-specific dermatoses among pregnant versus non-pregnant women of reproductive age.

Material and Methods: This descriptive hospital based study recruited 300 patients with skin lesions; the test group comprised 150 pregnant ladies while the control group comprised 150 non-pregnant female of reproductive age. Demographic characteristics, medical history, examination findings, and relevant investigation reports were noted and diagnosis established. The patients of test group were then classified into distinct subgroups of dermatoses and were compared with non-pregnant patients of control group.

Results: Specific dermatoses of pregnancy was very common (41.33\%) in our study among which Prurigo of pregnancy was the commonest (24\%). Inflammatory lesions were predominant in pregnant group $(57.33 \%, \mathrm{p}=<0.001)$ whereas infectious diseases were predominant in the non-pregnants (44.67\%). The demographic variables had no significant role in determining the distribution of any of the skin lesions in this study.

Conclusion: Inflammatory lesions mostly specific dermatoses of pregnancy are found to be the commonest skin lesions among the pregnant ladies whereas infectious diseases are found to be comparable among pregnant and non pregnant ladies in our study.

Keywords: Infectious dermatoses, Pregnancy dermatoses, Prurigo of pregnancy

\author{
Address of correspondence \\ Dr. Prabha Dawadi Bastola, \\ Lecturer of Dermatology and Venereology \\ KIST Medical College, Imadol Lalitpur Nepal \\ Email: prabhadawadi7@gmail.com
}




\section{Original Article}

\section{Introduction}

During pregnancy profound immunologic, metabolic, endocrine, and vascular changes occurs which make the pregnant woman susceptible to changes in the skin and appendages, both physiologic and pathologic and can lead to numerous skin findings in pregnancy. ${ }^{1}$ Alterations to the immune status of the pregnant woman are necessary to allow mothers to tolerate genetically different fetal tissues during pregnancy. These alterations lead to impaired cell mediated immunity with increased susceptibility to certain infections. Several inflammatory dermatoses are either unique to pregnancy or altered by the pregnant state. Human leukocyte antigen-G, in particular, seems to be important in protecting HLA mismatched tissue from the innate immune system. ${ }^{2}$

Pregnancy is associated with significant changes virtually in all the organ systems of the body including the skin. Pregnancy can have a positive as well as a negative effect on the course of preexisting skin diseases. ${ }^{3}$ Dermatoses specific to pregnancy are: pruritic urticarial papules and plaques of pregnancy (PUPPP), herpes gestationis (HG), cholestasis of pregnancy (pruritus gravidarum), impetigo herpetiformis and linear IgM dermatoses of pregnancy (LMDP). Some authors prefer the term "polymorphic eruption of pregnancy" (PUPP) to encompass PUPPP, prurigo of pregnancy and pruritic folliculitis of pregnancy. ${ }^{4}$

Many studies have been done to evaluate the frequency and clinical characteristics of pruritic dermatoses in different parts of the world. Because of the lack of studies, the socio-demographic and other epidemiological factors which govern the development, progression and the outcome of pregnancy dermatose is still largely unknown in this region. Therefore we designed this descriptive study to evaluate the magnitude, clinical characteristics and epidemiology of pregnancy dermatoses in patients attending Antenatal outpatient and Dermatology department of B P Koirala Institute of Health Sciences Dharan Nepal.

\section{Methodology}

This was a hospital based observational casecontrolled study, done over a period of one year. Three hundred patients were recruited, for the study after obtaining informed consent from them. In the test group 150 pregnant ladies with skin lesion who either came for antenatal check up and subsequently referred to Dermatology or the patient who directly came to dermatology OPD due to their skin aliments were taken. In the control group we took 150 non pregnant female of reproductive age group who visited dermatology OPD for the skin complaints.

A detailed obstetric history including parity and gestation, significant events in the previous pregnancy, if any, were noted so were any other medical history to rule out any systemic diseases. The patients were then examined thoroughly at the initial presentation by a dermatologist and full clinical details were noted. The personal and clinical data pertaining to patients such as clinical features, exacerbating and relieving factors, distribution, sites of involvement and morphology of skin changes were also recorded as per the preset proforma. Routine investigations including hemoglobin, blood group, HIV and VDRL serology and liver function tests were done in all the 150 pregnant patients. Skin testing such as $\mathrm{KOH}$ smear for fungus, Tzanck smear and skin biopsy were done only when they were felt necessary by the examining dermatologist.

The patients were then classified into distinct subgroups of pregnancy dermatoses depending on the clinical features and investigation reports. The frequency and mode of presentation, duration of illness, time of occurrence, lab investigation reports, association with the gravid status among the specific dermatoses of pregnancy were evaluated and compared. Patient of pregnant group are compared with non pregnant patients of control group to find out whether the pregnancy is related with increased frequency and severity of the disease process.

\section{Results}

The demographic profiles, relevant history and 


\section{Original Article}

physical examination findings, laboratory

association with pregnancy status were investigation reports, clinical diagnosis and their comparable in the two groups.

Table 1: Relative frequencies of different types of Dermatoses in the study

\begin{tabular}{|c|c|c|c|}
\hline \multirow{2}{*}{ Clinical diagnosis } & \multicolumn{2}{|c|}{ Group of patient No. (\%) } & \multirow{2}{*}{ Total No. (\%) } \\
\hline & Pregnant & Non-pregnant & \\
\hline Inflammatory & $86(57.33)$ & $44(29.33)$ & \multirow{13}{*}{$130(43.33)$} \\
\hline Urticaria & 9 & 10 & \\
\hline Pigmented purpuric dermatosis & 3 & 0 & \\
\hline DLE & 0 & 4 & \\
\hline PLC & 0 & 3 & \\
\hline PMLE & 3 & 2 & \\
\hline Acne vulgaris & 3 & 5 & \\
\hline Psoriasis vulgaris & 0 & 5 & \\
\hline Erythema nodosum & 4 & 3 & \\
\hline Lichen planus & 0 & 2 & \\
\hline Morphea & 0 & 6 & \\
\hline P rosea & 2 & 4 & \\
\hline Specific dermatoses of pregnancy & 62 & NA & \\
\hline Autoimmune disease & 0 & $27(18)$ & \multirow{7}{*}{$27(9)$} \\
\hline Pemphigus vulgaris & 0 & 2 & \\
\hline Vitiligo & 0 & 3 & \\
\hline SLE & 0 & 13 & \\
\hline Systemic sclerosis & 0 & 5 & \\
\hline Bullous pemphigoid & 0 & 2 & \\
\hline Pemphigus foliaceous & 0 & 2 & \\
\hline Infectious diseases & $55(36.67)$ & $67(44.67)$ & \multirow[t]{14}{*}{$122(40.67)$} \\
\hline Mycotic & 35 & 29 & \\
\hline Mycobacterial & 0 & 19 & \\
\hline Lupus vulgaris & 0 & 8 & \\
\hline Leprosy & 0 & 11 & \\
\hline Bacterial eg. furunculosis & 2 & 3 & \\
\hline Viral & 18 & 16 & \\
\hline Molluscum contagiosum & 2 & 0 & \\
\hline Herpes zoster & 3 & 5 & \\
\hline Herpes labialis & 1 & 3 & \\
\hline Herpes genitalis & 2 & 0 & \\
\hline Varicella zoster & 3 & 0 & \\
\hline Verruca vulgaris & 4 & 5 & \\
\hline Condyloma accuminata & 3 & 3 & \\
\hline Drug reaction & $4(2.67)$ & $5(3.33)$ & $9(3)$ \\
\hline Tumors & $3(2)$ & $7(4.67)$ & \multirow[t]{4}{*}{$10(3.33)$} \\
\hline Keloid & 1 & 4 & \\
\hline Hemangioma & 2 & 1 & \\
\hline Dermatofibroma & 0 & 2 & \\
\hline Others & $2(1.33)$ & 0 & \multirow[t]{2}{*}{$2(0.67)$} \\
\hline Ingrowing toe nail & 2 & 0 & \\
\hline Total & 150 & 150 & 300 \\
\hline
\end{tabular}

NJDVL - 40 


\section{Original Article}

Table 1 shows the relative frequencies of different types of Dermatoses in the study. Inflammatory diseases $130(43.335 \%)$ were the most common disease among all the patients in our study. The major bulk of the inflammatory diseases in the pregnant group was provided by specific dermatoses of pregnancy $62(41.33 \%)$. The commonest diseases to occur in the non-pregnant group were infectious 67 (44.67\%).

The specific dermatoses of pregnancy were Prurigo of pregnancy 36 (24\%) PUPP 11(7.33\%), ICP $9(6 \%)$ and Pruritic folliculitis of pregnancy $6(4 \%)$ (Table 2, Figure 1).

Table 2: Frequency of specific dermatoses of pregnancy.

\begin{tabular}{|l|c|c|c|}
\hline Diseases & $\begin{array}{c}\text { No. of } \\
\text { pati } \\
\text { ents }\end{array}$ & $\begin{array}{c}\text { Percentage } \\
\text { among } \\
\text { specific } \\
\text { dermatoses of } \\
\text { pregnancy }\end{array}$ & $\begin{array}{c}\text { Percentage } \\
\text { among all } \\
\text { pregnant } \\
\text { patients with } \\
\text { dermatoses }\end{array}$ \\
\hline $\begin{array}{l}\text { Prurigo of } \\
\text { pregnancy }\end{array}$ & 36 & 57.07 & 24 \\
\hline PUPP & 11 & 17.74 & 7.33 \\
\hline ICP & 9 & 14.52 & 6 \\
\hline $\begin{array}{l}\text { Pruritic folliculitis } \\
\text { of pregnancy }\end{array}$ & 6 & 9.67 & 4 \\
\hline Total & 62 & 100 & 41.33 \\
\hline
\end{tabular}

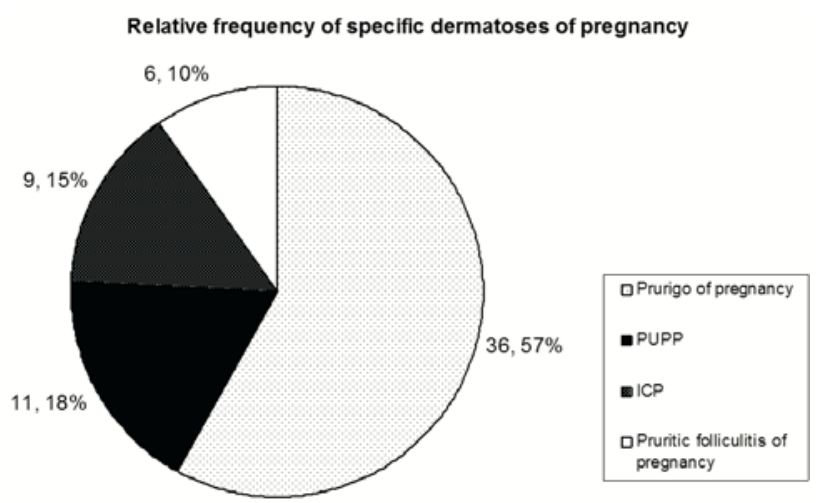

Figure 1: Relative frequency of specific dermatoses of pregnancy

Primigravida cases were found to be affected by specific dermatoses of pregnancy more frequently $46(74 \%)$ than multigravida and these patients were affected more in the third trimester of pregnancy. Pruritic folliculitis of pregnancy was equally prevalent in both primi and multigravida and that too in the $3^{\text {rd }}$ trimester of gestation. Among the multigravida, 49 (44.44\%) prurigo of pregnancy; 1 (33.33\%) of ICP, 1(100\%) of PUPP had history of similar lesion is their previous pregnancy (Table $3 \& 4$ ). None of the patients with specific dermatoses had a history of similar lesion prior to pregnancy.

Table 3: Obstetric history and Specific dermatoses of pregnancy

\begin{tabular}{|c|c|c|c|c|c|}
\hline \multirow{2}{*}{ Characteristic } & \multirow{2}{*}{ Categories } & \multicolumn{4}{|c|}{ No (\%) } \\
\hline & & ICP & PP & PUPP & PFP \\
\hline \multirow[t]{2}{*}{ Gravida } & Primi & $6(66.67)$ & $\begin{array}{c}27 \\
(75)\end{array}$ & $10(90.91)$ & $\begin{array}{c}3 \\
(50)\end{array}$ \\
\hline & Multi & $3(33.33)$ & $\begin{array}{c}9 \\
(25)\end{array}$ & $\begin{array}{c}1 \\
(9.09)\end{array}$ & $\begin{array}{c}3 \\
(50)\end{array}$ \\
\hline \multirow[t]{3}{*}{$\begin{array}{l}\text { Gestational age } \\
\text { In trimester }\end{array}$} & $1^{\text {st }}$ & 0 & $\begin{array}{c}1 \\
(2.78)\end{array}$ & 0 & $\begin{array}{c}1 \\
(16.67)\end{array}$ \\
\hline & $2^{\text {nd }}$ & $3(33.33)$ & $13(36.11)$ & 0 & $\begin{array}{c}1 \\
(16.67)\end{array}$ \\
\hline & $3^{\text {rd }}$ & $6(66.67)$ & $22(61.11)$ & $\begin{array}{c}11 \\
(100)\end{array}$ & $\begin{array}{c}4 \\
(66.67)\end{array}$ \\
\hline \multirow{2}{*}{$\begin{array}{l}\text { Similar lesion in } \\
\text { previous } \\
\text { pregnancy }\end{array}$} & Present & $1 / 3$ & $4 / 9$ & $1 / 1$ & $0 / 2$ \\
\hline & Absent & $3 / 3$ & $5 / 9$ & $0 / 1$ & $2 / 2$ \\
\hline \multirow{2}{*}{$\begin{array}{l}\text { Similar lesion } \\
\text { prior to } \\
\text { pregnancy }\end{array}$} & Present & $0(0)$ & $0(0)$ & $0(0)$ & $\begin{array}{l}0 \\
(0)\end{array}$ \\
\hline & Absent & $9(100)$ & $\begin{array}{c}36 \\
(100)\end{array}$ & $\begin{array}{c}11 \\
(100)\end{array}$ & $\begin{array}{c}6 \\
(100)\end{array}$ \\
\hline \multirow[t]{2}{*}{ Past treatment } & Yes & $0(0)$ & $\begin{array}{c}3 \\
(8.33)\end{array}$ & $0(0)$ & $\begin{array}{c}1 \\
(16.67)\end{array}$ \\
\hline & No & $9(100)$ & $33(91.67)$ & $\begin{array}{c}11 \\
(100)\end{array}$ & $\begin{array}{c}5 \\
(83.33)\end{array}$ \\
\hline \multirow{2}{*}{$\begin{array}{l}\text { Improvement } \\
\text { from past } \\
\text { treatment }\end{array}$} & Yes & - & $1 / 3$ & - & $1 / 1$ \\
\hline & No & - & $2 / 3$ & - & $0 / 1$ \\
\hline
\end{tabular}

Table 4: Comparison of Specific dermatoses of pregnancy with respect to maternal and gestational age.

\begin{tabular}{|l|c|c|c|}
\hline \multirow{2}{*}{ Diseases } & \multicolumn{3}{|c|}{ Mean ( \pm SD) } \\
\cline { 2 - 4 } & Age (years) & $\begin{array}{c}\text { Gestational } \\
\text { age in weeks }\end{array}$ & $\begin{array}{c}\text { Duration of } \\
\text { illness in days }\end{array}$ \\
\hline ICP & $23.22(2.86)$ & $30.11(7.25)$ & $13.44(8.46)$ \\
\hline $\begin{array}{l}\text { Prurigo of } \\
\text { pregnancy }\end{array}$ & $23.25(4.12)$ & $26.94(7.30)$ & $31.94(34.90)$ \\
\hline PUPP & $22.91(3.08)$ & $35.91(2.98)$ & $4.91(2.39)$ \\
\hline $\begin{array}{l}\text { Pruritic folliculitis } \\
\text { of pregnancy }\end{array}$ & $27.33(3.44)$ & $24.83(9.77)$ & $15.33(9.03)$ \\
\hline
\end{tabular}




\section{Original Article}

\section{Discussion}

Pregnancy is associated with significant changes virtually in all the organ systems of the body including the skin. Due to the altered state of physiologic homeostasis, hormonal status and immunity during pregnancy, these have some definite impact on the skin diseases; some are worsened, some are not affected while a few of them have got positive effects. The overall incidence of these specific disorders of pregnancy is 0.5 to $3.0 \%$ of all pregnancies. ${ }^{5}$ Whereas the incidence of each of the diseases are: ICP 0.232.4\%, PEP 1:160, PP 1:300, PG 1:40 000-60 000 and $\mathrm{PF}$ probably rare. ${ }^{3}$

In our study, the skin lesions mostly seen in the cases were inflammatory in nature followed by infectious. Whereas in the control group, infectious diseases were commonest followed by inflammatory then autoimmune. Other minor skin lesions we came across in both the groups were superficial skin tumors and drug reactions. The increased incidence of certain infections in pregnancy may be attributed to the immunosuppressive effects of high serum levels of estrogens that occours during pregnancy. These include a decrease in cell-mediated immunity, neutrophil function, and activity of natural killer cells, as well as impairment of local antibody responses. $^{6}$

In our study almost all patients 290 out of 300 (96.67\%) belonged to the plains and only 10 out of $300(3.33 \%)$ were from the hilly regions. This shows that in our study skin diseases prevails more in the plains as compared to the hills. This could be related to the hot and humid climate of tarai as compared to the cooler climate of the hilly areas. Besides these the occurrence of the dermatoses were not significantly governed by the socio-demographic profiles of the patients. No significant variation in education, and occupation was observed in patient of different types of dermatoses.

Frequency of specific dermatoses is found to be very high in our study, which may to some extent be due to essentially clinical diagnosis we made, with very minimal supportive investigations. We were unable to do hormonal assays, immunofluorescence and level of immunoglobulin to facilitate the diagnosis due to the unavailability of the facilities to do so. It is very important to note that clinical diagnosis of pregnancy dermatoses is a challenge even for experienced dermatologists. ${ }^{6}$ Biopsy also were done in very few number of patients due to its negative cost benefit ratio.

Despite the frequent association between pregnancy and a skin eruption, there have been few prospective studies addressing it. ${ }^{5}$ In the study done by Shivakumar and Madhavamurthy where in the total patients were 170, $16(9.41 \%)$ patients had prurigo of pregnancy, $6(3.52 \%)$ ICP and $4(2.35 \%)$ had PUPP. ${ }^{7}$ A prospective study by Roger et al. studied 59 pregnant women with itching over the period of a year. Twenty-two patients presented with ICP alone while PUPP accounted for 25, PG for two, prurigo for seven, $\mathrm{PF}$ for one and only two women presented with an undercurrent skin diseases. ${ }^{8}$ Whereas in our study of 150 pregnant women, $62(41.52 \%)$ cases of specific dermatoses of pregnancy were seen. Of these the most common was prurigo of pregnancy $36(24 \%)$ followed by PUPP 11 $(7.33 \%)$, ICP $9(6 \%)$, pruritic folliculitis of pregnancy $6(4 \%)$ and other dermatoses not related to pregnancy $87(59 \%)$.

Other dermatoses not related to pregnancy found in our study were fungal infection $35(23.33 \%)$, viral infection $18(12 \%)$, urticarial $9(6 \%)$, erythema nodosum 4 (2.67\%), polymorphous light eruption $3(2 \%)$, acne vulgaris $3(2 \%)$, pigmented purpuric dermatoses $3(2 \%)$, bacterial infections $2(1.33 \%)$ and Pityriasis rosea 2 $(1.33 \%)$. Among the fungal infections tinea was the commonest followed by candidiasis. Among viral, herpes infection was the commonest. Certain dermatoses like fungal infection viral infection and acne were found to be exacerbated during pregnancy. Normal pregnancy is characterized by a lack of strong maternal cell mediated immunity and a dominant humoral immune response which might be the reason for high 


\section{Original Article}

infection rates during pregnancy. ${ }^{9}$ The increased incidence of certain infections in pregnancy has been also attributed to the immunosuppressive effects of high serum levels of estrogens. These include a decrease in cell-mediated immunity, neutrophil function, and activity of natural killer cells, as well as impairment of local antibody responses.

In one study done by Ambros-Rudolph et al, they have found inflammatory diseases $(52 \%)$ to be the commonest miscellaneous skin disease coinciding with pregnancy followed by infection (26\%) and drug reactions $11.5 \%{ }^{3}$. Whereas in our study, among the miscellaneous skin disease coinciding with pregnancy, infectious were the commonest $(36.67 \%)$, followed by inflammatory disease $(16 \%)$ and drug reaction $(2.67 \%)$. This explains that infectious diseases are the commonest skin diseases that occours in our region.

In an Indian study, done by Shivakumar and Madhavamurthy, they have found pruritus to be the commonest symptom (58.82\%). Our finding was consistent with this as most of the patient in the pregnant group of our study $(76.67 \%)$ had pruritus of varying intensity. ${ }^{7}$

As per Kroumpouzos G et al. Prurigo of pregnancy is the most frequent pruritic dermatoses in pregnancy and includes eczematous or papular lesions in patients with a personal and/or family history of atopy. ${ }^{6}$ In our study also among the cases, $18(12 \%)$ had history of atopy in the form of recurrent allergic rhinitis $10(55.56 \%)$, family history of asthma $6(33.33 \%)$, eczematous skin condition $3(16 \%)$ and urticaria 2 (11.11\%). Reduced cellular immunity and reduced production of Th1 cytokines (IL-2, interferon gamma, IL-12) stand-in contrast to the dominant humoral immunity and increased secretion of Th2 cytokines (IL-4, IL-10) in pregnancy. Interleukin-4 is known to be central to the induction of B-lymphocyte synthesis of IgE which might be relevant to atopic disease in pregnancy. ${ }^{10}$ ICP usually manifests in the third trimester by itchiness (pruritus gravidarum) and skin lesions caused by scratching. Jaundice develops in $20 \%$ of cases (intrahepatic jaundice of pregnancy). There is a family history in $50 \%$ of cases and an association with multiple gestation. ${ }^{11}$ Recurrence in subsequent pregnancies occur in $60 \%$ to $70 \%$ of cases. The condition usually resolves within the first month after delivery. ${ }^{12}$ Our patients of ICP also manifested its signs and symptoms in the third trimester with mean gestational age of $30.11 \pm 7.25$ weeks. Two of our patients with ICP developed jaundice which was found in both second and third trimester and one patient gave history of similar lesion in previous pregnancy as well.

Another interesting finding in our study was that only 2 patients had multiple gestations and both of them presented with PEP. Different studies have suggested that multiple gestation is a triggering factor for the development of PEP. ${ }^{13}$ In a recent meta-analysis, a higher prevalence of multiple gestation pregnancy (11.7\%) among patients with PEP was observed and interestingly the majority were twin pregnancies $(9.92 \%)$. The authors suggested that increased abdominal distension may be a trigger eliciting the occurrence of PEP in these pregnancies. ${ }^{6}$

Pruritic folliculitis of pregnancy was seen in only 6 (4\%) women who presented with generalized red, follicular papules. These were distributed on the chest and back. This disorder was seen in the 2 nd and $3^{\text {rd }}$ trimester with mean age of gestation of 24.83 \pm 9.77 weeks. Pruritic folliculitis of pregnancy (PFP) was first described by Zoberman and Farmer in 1981. ${ }^{14}$ The lesions were generalized, erythematous, follicular papules, which developed from the fourth to the ninth month of gestation it is likely that many cases of PFP are misdiagnosed as microbial folliculitis. ${ }^{14}$ Wilkinson et al. suggested that PFP might be a form of hormonally induced acne, caused by endorgan hypersensitivity to increased serum levels of sex hormones during pregnancy. ${ }^{15}$ There has been little additional evidence in favor of this hypothesis.

Since ours was a cross-sectional hospital based 


\section{Original Article}

study we are unable to comment on incidence, progress and the impact of these skin lesions on the outcome of pregnancy.

\section{Conclusion}

Inflammatory lesions mostly specific dermatoses of pregnancy are found to be the commonest skin lesions among the pregnant ladies whereas infectious diseases are found to be comparable among pregnant and non pregnant ladies in our study. A larger scale, community based and prospective study is needed to clearify, validate and further strengthen what we have found in this study on the pregnancy dermatoses.

\section{References}

1. Samdani AJ. Pregnancy Dermatoses: A Three- year study. Pak J Med Sci 2004; 20: 292-5.

2. Yip L, McCluskey J, Sinclair R. Immunological aspects of pregnancy: Clin Dermatol 2006; 24: 84-7. http://dx.doi.org/10.1016/j.clindermatol.2005.10.022

3. Ambros-Rudolph CM, Müllegger RR, Vaughan-Jones SA, Kerl H, Black MM. The specific dermatoses of pregnancy revisited and reclassified. Results of a retrospective two-center study on 505 pregnant patients. J Am Acad Dermatol 2006; 54: 395-40. http://dx.doi.org/10.1016/j.jaad.2005.12.012

4. Cohen LM. Dermatoses of Pregnancy. WJM 1998; 169: 223-4.

5. Kumari R, Jaisankar TJ, Thappa DM. A clinical study of skin changes in pregnancy. Indian J Dermatol Venereol Leprol 2007; 73: 141. http://dx.doi.org/10.4103/0378-6323.31910

6. Kroumpouzos G, Cohen LM. Dermatoses of pregnancy. J Am Acad Dermatol 2001; 45: 1-19. http://dx.doi.org/10.1067/mjd.2001.114595

7. Shivakumar V, Madhavamurthy P. Skin in pregnancy. Indian J Dermatol Venereol Leprol 1999; 65: $23-5$.

8. Roger D, Vaillant L, Fignon A, Pierre F, Bacq Y, Brechot J-F, et al. Specific pruritic dermatoses of pregnancy: a prospective study of 31women. Arch Dermatol 1994; 130: 734-9. http://dx.doi.org/10.1001/archderm.1994.01690060064006

9. GarcõÂa-Gonza Â, Ahued-Ahued R, Arroyo E, Montes-De-Oca D, Granados J. Immunology of the cutaneous disorders of pregnancy. Int J Dermatol 1999; 38: 721-9. http://dx.doi.org/10.1046/j.1365-4362.1999.00810.x

10. Kroumpouzos G, Cohen LM. Specific Dermatoses of pregnancy: an evidence based systemic review. Am J Obstet Gynecol 2003; 188: 1083-92. http://dx.doi.org/10.1067/mob.2003.129

11. Knox TA, Olans LB. Liver disease in pregnancy. N Engl J Med 1996; 335: 56976.http://dx.doi.org/10.1056/NEJM199608223350807

12. Lammert F, Marshall HU, Glantz A, Matern S. Intrahepatic cholestasis of pregnancy: Molecular pathogenesis, diagnosis and management. J Hepatol 2000; 33: 1012-21. http://dx.doi.org/10.1016/S0168-8278(00)80139-7

13. Petropoulos H, Georgala S, Katsambas AD. Polymorphic eruption of pregnancy. Int J Dermatol 2006; 45: 642-8. http://dx.doi.org/10.1111/j.1365-4632.2006.02715.x

14. Zoberman E, Farmer ER. Pruritic folliculitis of pregnancy. Arch Dermatol 1981; 117: 20-2. http://dx.doi.org/10.1001/archderm.1981.01650010026017

15. Sasseville D, Wilkinson RD and Schnader JY. Dermatoses of Pregnancy. Int J Dermatol 1981; 20: 223-4 http://dx.doi.org/10.1111/j.1365-4362.1981.tb04327.x 